\title{
Attitudes toward metabolic adverse events among patients with schizophrenia in Japan
}

\author{
This article was published in the following Dove Press journal: \\ Neuropsychiatric Disease and Treatment \\ 24 February 2016 \\ Number of times this article has been viewed
}

\author{
Norio Sugawara ${ }^{1-3}$ \\ Norio Yasui-Furukori ${ }^{2,3}$ \\ Manabu Yamazaki ${ }^{4}$ \\ Kazutaka Shimoda ${ }^{3,5}$ \\ Takao Mori ${ }^{4}$ \\ Takuro Sugai ${ }^{3,6}$ \\ Hiroshi Matsuda ${ }^{4}$ \\ Yutaro Suzuki $i^{3,6}$ \\ Yoshitake Minami ${ }^{4}$ \\ Yuji Ozeki ${ }^{3,5}$ \\ Kurefu Okamoto ${ }^{4}$ \\ Toyoaki Sagae ${ }^{7}$ \\ Toshiyuki Someya ${ }^{3,6}$ \\ 'Aomori Prefectural Center for \\ Mental Health and Welfare, Aomori, \\ 2Department of Neuropsychiatry, \\ Hirosaki University School of \\ Medicine, Hirosaki, JJapanese Society \\ of Clinical Neuropsychopharmacology, \\ ${ }^{4}$ Japan Psychiatric Hospital \\ Association, Tokyo, ${ }^{5}$ Department \\ of Psychiatry, Dokkyo Medical \\ University School of Medicine, Mibu, \\ ${ }^{6}$ Department of Psychiatry, Niigata \\ University Graduate School of \\ Medical and Dental Sciences, Niigata, \\ ${ }^{7}$ Department of Health and Nutrition, \\ Yamagata Prefectural Yonezawa \\ University of Nutrition Sciences, \\ Yonezawa, Japan
}

Correspondence: Norio Sugawara

Aomori Prefectural Center for Mental

Health and Welfare, 353-92 Sawabe

Sannai, Aomori city 038-003I, Aomori,

Japan

Tel +8I I 7787395 ।

Fax +8I I77873956

Email nsuga3@yahoo.co.jp
Background: Metabolic syndrome is a growing concern among patients with schizophrenia because metabolic abnormalities are widely regarded as a major risk factor for cardiovascular disease and premature death. The current study assessed attitudes toward metabolic adverse events among patients with schizophrenia.

Methods: A brief questionnaire was constructed to investigate patient recognition of the following broad areas: dietary habits, lifestyle, self-monitoring, knowledge, and medical practice. Between January 2012 and June 2013, questionnaires were sent to patients associated with 520 outpatient facilities and 247 inpatient facilities belonging to the Japan Psychiatric Hospital Association. All of the participants ( $n=22,072$; inpatients $=15,170$, outpatients =6,902) were diagnosed with schizophrenia based on the Diagnostic and Statistical Manual of Mental Disorders, fourth edition, or the International Classification of Diseases, tenth revision.

Results: Approximately 55.0\% $(8,069 / 14,669)$ of inpatients and $44.8 \%$ of outpatients $(2,978 / 6,649)$ reported that they did not exercise at all. Although $60.9 \%(4,116 / 6,760)$ of outpatients reported that they felt obese, only $35.6 \%(5,261 / 14,794)$ of inpatients felt obese. More than half of the inpatients $(51.2 \% ; 7,514 / 14,690)$ and outpatients $(60.8 \% ; 4,086 / 6,721)$ hoped to receive regular blood tests to prevent weight gain and diseases such as diabetes.

Conclusion: Although more than half of patients hoped to prevent weight gain and diabetes, only a minority of patients were mindful of eating balanced meals and having physical exercise. Educational efforts and the promotion of the best pharmacotherapy and monitoring practices are needed for patients with schizophrenia.

Keywords: metabolic syndrome, schizophrenia, attitude, Japan

\section{Introduction}

Metabolic syndrome (MetS) is a growing concern among patients with schizophrenia ${ }^{1}$ because metabolic adverse events are widely regarded as a major risk factor for cardiovascular diseases ${ }^{2,3}$ and mortality. ${ }^{4,5}$ Although the causes of metabolic adverse events are complicated, the risk factors among patients with schizophrenia are attributed to dietary habits, ${ }^{6}$ physical activity, ${ }^{7}$ antipsychotic medications,${ }^{8,9}$ and negative symptoms of schizophrenia. ${ }^{10}$

Although the opinion of psychiatrists is well known concerning this issue,${ }^{11-14}$ those of the patients most affected by metabolic adverse events are relatively unexplored; nevertheless, they are important factors. Educational programs for these patients might effectively improve their clinical outcomes. ${ }^{15}$ To date, some studies have assessed patient attitudes toward antipsychotic medications. ${ }^{16-20}$ However, these studies have not primarily focused on metabolic adverse events. Thus, it is necessary to accurately assess patient attitudes toward metabolic issues in a representative sample of patients. 
Currently, Japan has 28.4 psychiatric beds per 10,000 people, which is the highest ratio in the world. Furthermore, the mean length of hospital stay in Japan is $\sim 1.5$ years, which represents the longest stay among developed nations. ${ }^{21}$ Because inpatients with schizophrenia receive controlled meals and occupational therapy, their lifestyles might differ from those of outpatients. A previous study conducted in Japan showed that the rates of MetS in outpatients and inpatients with schizophrenia were $48.1 \%$ and $15.8 \%$, respectively. ${ }^{22}$ Although the shift from inpatient care to community-based care is an ongoing challenge, the discharge of long-term psychiatric patients might elevate their risk of MetS. We previously reported the psychiatrists' attitudes toward metabolic adverse events in patients with schizophrenia. ${ }^{14}$ However, attitudes of schizophrenic patients themselves had not been assessed in Japan.

The current study investigated attitudes toward metabolic adverse events in a nationwide survey of Japanese patients with schizophrenia. To our knowledge, this study uses the largest sample of these patients, and it is the first to investigate attitudes toward metabolic issues among Asian patients.

\section{Methods}

\section{Procedure}

The joint committee of the Japanese Society of Clinical Neuropsychopharmacology and the Japan Psychiatric Hospital Association for antipsychotic treatment and physical risk prepared this survey. After reviewing the relevant literature and extant guidelines, a brief questionnaire was constructed to cover patient recognition of the following broad areas: dietary habits, lifestyle, self-monitoring, knowledge, and medical practice (Figure S1). Between January 2012 and June 2013, the questionnaire was mailed to patients associated with 520 outpatient facilities and 247 inpatient facilities belonging to the Japan Psychiatric Hospital Association. Participants have been selected based on the available sampling method and diagnosed with schizophrenia according to the Diagnostic and Statistical Manual of Mental Disorders, fourth edition, or International Classification of Diseases, tenth revision.
All respondents provided written informed consent to participate in this study without any incentive. The anonymous questionnaire was the only research instrument, and a statement was included that states, "The completion of the attached questionnaire will be taken as indicating your consent to participate". The Ethics Committee at the Japan Psychiatric Hospital Association and the Hirosaki University School of Medicine approved the study procedure.

\section{Statistical analysis}

Descriptive statistics were computed to describe the demographic and clinical variables. In order to compare the main demographic and clinical characteristics between inpatients and outpatients, the Mann-Whitney $U$-test was performed to analyze continuous variables, and a chi-square test was performed to analyze categorical variables. A value of $P<0.05$ was considered significant. Parameter $r$ was used to measure the effect size of Mann-Whitney $U$-test, and $r$ values of 0.3 represent medium effect sizes. Strength of association on a chi-square analysis was confirmed with a medium phi and Cramer's $V$ score of 0.30 . The data were analyzed using the SPSS software for Windows (Version 23.0).

\section{Results}

The demographic characteristics of the study participants are listed in Table 1.

\section{Patient recognition of dietary habits}

Approximately $27.9 \%(4,136 / 14,840)$ of inpatients stated that they drank soft drinks (eg, cola; Q1) every day, $34.6 \%(5,142 / 14,840)$ did so more than once a week, $18.3 \%(2,718 / 14,840)$ did so more than once a month, and $19.2 \%(2,844 / 14,840)$ did not drink any, whereas $27.8 \%$ $(1,841 / 6,616)$ of outpatients stated that they drank soft drinks every day, $28.5 \%(1,884 / 6,616)$ did so more than once a week, $25.8 \%(1,706 / 6,616)$ did so more than once a month, and $17.9 \%(1,185 / 6,616)$ did not drink any (Q1; Cramer's $V=0.092, P<0.001)$. Approximately $62.8 \%(9,324 / 14,841)$ of inpatients consumed $100 \%$ of three meals a day (Q2),

Table I Participant characteristics $(n=22,072)$

\begin{tabular}{|c|c|c|c|c|c|c|c|}
\hline & \multicolumn{2}{|c|}{ Inpatients } & \multicolumn{2}{|c|}{ Outpatients } & \multirow[t]{2}{*}{$P$-value } & \multicolumn{2}{|l|}{ Total } \\
\hline & Mean & SD & Mean & SD & & Mean & SD \\
\hline Age (years) & 60.1 & 13.0 & 52.7 & 15.0 & $<0.001(r=0.26)$ & 57.8 & 14.I \\
\hline \multicolumn{8}{|l|}{ Sex } \\
\hline Male & 7,994 & & 3,953 & & $<0.001(\mathrm{phi}=0.043)$ & 11,947 & \\
\hline Female & 7,176 & & 2,949 & & & 10,125 & \\
\hline
\end{tabular}

Notes: Phi represents the effect size for chi-square test; $r$ represents the effect size for Mann-Whitney $U$-test.

Abbreviation: SD, standard deviation. 
$12.2 \%(1,806 / 14,841)$ ate $90 \%, 12.1 \%(1,790 / 14,841)$ ate $80 \%, 5.8 \%(860 / 14,841)$ ate $70 \%, 4.3 \%(644 / 14,841)$ ate $60 \%$, and $2.8 \%(417 / 14,841)$ ate $\leq 50 \%$. Approximately $82.6 \%(5,633 / 6,823)$ of outpatients stated that they regularly ate breakfast, lunch, and dinner. Approximately 39.3\% $(5,855 / 14,914)$ of inpatients and $36.3 \%(2,466 / 6,799)$ of outpatients stated that they ate cake or other sweets more than once a day $(\mathrm{Q} 3$; phi $=0.029, P<0.001)$. Approximately $17.0 \%(2,523 / 14,865)$ of inpatients were warned not to eat too many snacks (Q4). Approximately 36.7\% $(2,490 / 6,784)$ of outpatients were also warned not to eat too many meals (Q4). Only 6.9\% $(1,008 / 14,674)$ of inpatients and $6.5 \%(442 / 6,779)$ of outpatients stated that they generally take sweets when they go out or stay out overnight (Q5). Approximately 41.7\% $(6,152 / 14,765)$ of inpatients and $25.3 \%(1,709 / 6,767)$ of outpatients stated that they were always hungry (Q6; phi $=0.158, P<0.001)$. Approximately $59.3 \%(3,856 / 6,505)$ of outpatients stated that they cook or do housework by themselves (Q9).

\section{Patient recognition of lifestyle}

Approximately $8.4 \%(1,071 / 12,751)$ of inpatients reported going out every day (Q8), 12.2\% (1,558/12,751) went out more than once a week, $16.9 \%(2,150 / 12,751)$ went out more than once a month, and $62.5 \%(7,972 / 12,751)$ did not go out at all; these percentages were $46.6 \%(3,091 / 6,627), 31.8 \%$ $(2,110 / 6,627), 13.3 \%(883 / 6,627)$, and $8.2 \%(543 / 6,627)$ among outpatients, respectively (Q8; Cramer's $V=0.593$, $P<0.001)$. Approximately $18.5 \%(2,708 / 14,669)$ of inpatients reported exercising every day (Q10), 13.1\% $(1,923 / 14,669)$ did so once a week, $13.4 \%(1,969 / 14,669)$ did so more than once a week, and 55.0\% $(8,069 / 14,669)$ did not exercise at all; these percentages were $20.2 \%(1,342 / 6,649), 14.8 \%$ (986/6,649), 20.2\% (1,343/6,649), and 44.8\% $(2,978 / 6,649)$ among outpatients, respectively (Q10; Cramer's $V=0.107$, $P<0.001)$. Approximately $35.2 \%(5,231 / 14,864)$ of inpatients reported watching television every day (Q11), 49.1\% $(7,305 / 14,864)$ watched television sometimes, and $15.7 \%$ $(2,328 / 14,864)$ watched none at all; these percentages were $60.4 \%(4,077 / 6,748), 30.3 \%(2,047 / 6,748)$, and $9.2 \%$ $(624 / 6,748)$ among outpatients, respectively (Q11; Cramer's $V=0.236, P<0.001)$.

\section{Patient recognition of self-monitoring}

In this survey, $33.1 \%(4,859 / 14,701)$ of inpatients and $48.4 \%$ $(3,229 / 6,669)$ of outpatients reported that they gained weight over the previous year (Q7; phi $=0.147, P<0.001)$. Approximately $22.9 \%(1,554 / 6,781)$ of outpatients stated that they weighed themselves every day (Q15), 21.0\% (1,427/6,781) did so more than once a week, $19.3 \%(1,306 / 6,781)$ did so more than once a month, and 36.8\% $(2,494 / 6,781)$ did not weigh themselves at all. Table 2 shows the healthy habits of which patients were mindful (Q19). With regard to body weight self-assessments (Q20), 35.6\% $(5,261 / 14,794)$ of inpatients and $60.9 \%(4,116 / 6,760)$ of outpatients felt that they were obese (Q20; phi $=0.237, P<0.001)$.

\section{Patient recognition of knowledge}

Approximately $16.4 \%(2,412 / 14,735)$ of inpatients and $23.2 \%(1,552 / 6,693)$ of outpatients stated that their doctor educated them on how their medication might cause side effects such as weight gain (Q12; phi $=0.081, P<0.001)$. Furthermore, $31.9 \%(4,749 / 14,883)$ of inpatients and $74.3 \%$ $(5,056 / 6,809)$ of outpatients knew the term "metabolic syndrome" (Q16; phi $=0.395, P<0.001)$. Additionally, 9.7\% $(1,431 / 14,742)$ of inpatients and $22.8 \%(1,530 / 6,720)$ of outpatients knew the terms "BMI" or "body mass index" (Q17; phi $=0.176, P<0.001$ ).

\section{Patient recognition of medical practice}

Approximately $10.2 \%(1,517 / 14,823)$ of inpatients stated that their body weight was measured at the hospital every day (Q13), 13.7\% (2,033/14,823) said they were weighed once a week, 74.1\% $(10,984 / 14,823)$ said they were weighed once a month, $0.8 \%(121 / 14,823)$ said they were weighed at least once every 6 months, $0.6 \%(96 / 14,823)$ said they were weighed at least once a year, and $0.5 \%(72 / 14,823)$ said that they were never weighed; $27.9 \%(1,792 / 6,421)$ of outpatients stated that their body weight was measured at the hospital every visit, $19.3 \%(1,238 / 6,421)$ said they were weighed at least once every 3 months, 6.6\% $(423 / 6,421)$ said they were weighed at least once every 6 months, $10.1 \%$ $(651 / 6,421)$ said they were weighed at least once a year, and $36.1 \%(2,317 / 6,421)$ said that they were never weighed. Approximately $40.2 \%(5,814 / 14,473)$ of inpatients stated that they had blood tests at a hospital (Q14) every month, 37.5\% $(5,425 / 14,473)$ had blood tests at least once every 3 months, $15.5 \%(2,239 / 14,473)$ had blood tests at least once every 6 months, 5.5\% $(799 / 14,473)$ had blood tests at least once a year, and 1.4\% (196/14,473) never had blood tests; $7.2 \%$ $(464 / 6,468)$ of outpatients stated that they had blood tests at the hospital every visit, $27.4 \%(1,769 / 6,468)$ said they had blood tests at least once every 3 months, $24.5 \%(1,587 / 6,468)$ said they had blood tests at least once every 6 months, $24.4 \%$ $(1,579 / 6,468)$ said they had blood tests at least once a year, and $16.5 \%(1,069 / 6,468)$ said that they never had blood tests. Table 3 lists the healthy habits that patients were told to be mindful of by their doctors (Q18). To prevent weight 
Table 2 Healthy habits of which patients are mindful

\begin{tabular}{|c|c|c|c|c|c|c|}
\hline \multirow[b]{2}{*}{ Eating a balanced meal } & \multicolumn{2}{|c|}{ Inpatients } & \multicolumn{2}{|c|}{ Outpatients } & \multirow{2}{*}{$\begin{array}{l}\text { Phi value } \\
0.178\end{array}$} & \multirow{2}{*}{$\begin{array}{c}P \text {-value } \\
<0.001\end{array}$} \\
\hline & $26.7 \%$ & $(4,044 / 15,170)$ & $44.6 \%$ & $(3,080 / 6,902)$ & & \\
\hline Male & $24.7 \%$ & $(1,975 / 7,994)$ & $41.6 \%$ & $(1,645 / 3,953)$ & 0.173 & $<0.001$ \\
\hline Female & $28.8 \%$ & $(2,069 / 7,176)$ & $48.7 \%$ & $(1,435 / 2,949)$ & 0.189 & $<0.001$ \\
\hline Refraining from fast food & $13.9 \%$ & $(2,109 / 15,170)$ & $26.2 \%$ & $(1,808 / 6,902)$ & 0.149 & $<0.001$ \\
\hline Male & $13.7 \%$ & $(1,094 / 7,994)$ & $23.3 \%$ & $(923 / 3,953)$ & 0.121 & $<0.001$ \\
\hline Female & $14.1 \%$ & $(I, 0 \mid 5 / 7,176)$ & $30.0 \%$ & $(885 / 2,949)$ & 0.185 & $<0.001$ \\
\hline Refraining from soft drinks (eg, cola) & $20.7 \%$ & $(3,145 / 15,170)$ & $32.9 \%$ & $(2,27 / / 6,902)$ & 0.131 & $<0.001$ \\
\hline Male & $19.7 \%$ & $(1,575 / 7,994)$ & $30.4 \%$ & $(1,202 / 3,953)$ & 0.119 & $<0.001$ \\
\hline Female & $21.9 \%$ & $(1,570 / 7,176)$ & $36.2 \%$ & $(1,069 / 2,949)$ & 0.149 & $<0.001$ \\
\hline Refraining from alcohol & $14.8 \%$ & $(2,244 / 15,170)$ & $33.1 \%$ & $(2,288 / 6,902)$ & 0.211 & $<0.001$ \\
\hline Male & $16.9 \%$ & $(1,354 / 7,994)$ & $36.3 \%$ & $(1,433 / 3,953)$ & 0.215 & $<0.001$ \\
\hline Female & $12.4 \%$ & $(890 / 7,176)$ & $29.0 \%$ & $(855 / 2,949)$ & 0.200 & $<0.001$ \\
\hline Refraining from smoking & $19.3 \%$ & $(2,931 / 15,170)$ & $30.7 \%$ & $(2,118 / 6,902)$ & 0.125 & $<0.001$ \\
\hline Male & $23.7 \%$ & $(1,894 / 7,994)$ & $33.8 \%$ & $(1,337 / 3,953)$ & 0.107 & $<0.001$ \\
\hline Female & $14.5 \%$ & $(1,037 / 7,176)$ & $26.5 \%$ & $(781 / 2,949)$ & 0.142 & $<0.001$ \\
\hline Sleeping enough & $31.0 \%$ & $(4,708 / 15,170)$ & $46.2 \%$ & $(3,188 / 6,902)$ & 0.147 & $<0.001$ \\
\hline Male & $31.2 \%$ & $(2,498 / 7,994)$ & $45.6 \%$ & $(1,803 / 3,953)$ & 0.141 & $<0.001$ \\
\hline Female & $30.8 \%$ & $(2,210 / 7,176)$ & $47.0 \%$ & $(1,385 / 2,949)$ & 0.154 & $<0.001$ \\
\hline Moderate physical exercise & $29.4 \%$ & $(4,464 / 15,170)$ & $39.5 \%$ & $(2,724 / 6,902)$ & 0.099 & $<0.001$ \\
\hline Male & $29.3 \%$ & $(2,339 / 7,994)$ & $39.1 \%$ & $(1,546 / 3,953)$ & 0.099 & $<0.001$ \\
\hline Female & $29.6 \%$ & $(2,|25 / 7| 76)$, & $39.9 \%$ & $(1,178 / 2,949)$ & 0.100 & $<0.001$ \\
\hline Other & $5.8 \%$ & $(883 / 15,170)$ & $3.4 \%$ & $(237 / 6,902)$ & 0.050 & $<0.001$ \\
\hline Male & $5.4 \%$ & $(435 / 7,994)$ & $3.1 \%$ & $(123 / 3,953)$ & 0.052 & $<0.001$ \\
\hline Female & $6.2 \%$ & $(448 / 7,176)$ & $3.9 \%$ & $(114 / 2,949)$ & 0.047 & $<0.001$ \\
\hline None & $31.8 \%$ & $(4,83|/| 5, \mid 70)$ & $12.9 \%$ & $(887 / 6,902)$ & 0.201 & $<0.001$ \\
\hline Male & $30.9 \%$ & $(2,468 / 7,994)$ & $12.5 \%$ & $(493 / 3,953)$ & 0.201 & $<0.001$ \\
\hline Female & $32.9 \%$ & $(2,363 / 7, \mid 76)$ & $13.4 \%$ & $(394 / 2,949)$ & 0.200 & $<0.001$ \\
\hline
\end{tabular}

Notes: Phi represents the effect size for chi-square test; "Other" participants answered that they are mindful of other healthy habits; "None" participants answered that they are not mindful of any healthy habits.

Table 3 Healthy habits that patients were encouraged to be mindful of by their doctors

\begin{tabular}{|c|c|c|c|c|c|c|}
\hline \multirow[b]{2}{*}{$\begin{array}{l}\text { Eating balanced meals and } \\
\text { appropriate amounts of food }\end{array}$} & \multicolumn{2}{|c|}{ Inpatients } & \multicolumn{2}{|c|}{ Outpatients } & \multirow{2}{*}{$\begin{array}{l}\text { Phi value } \\
0.103\end{array}$} & \multirow{2}{*}{$\frac{P \text {-value }}{<0.001}$} \\
\hline & $12.5 \%$ & $(1,897 / 15,170)$ & $20.4 \%$ & $(1,4 \mid 0 / 6,902)$ & & \\
\hline Male & $11.5 \%$ & $(922 / 7,994)$ & $19.4 \%$ & $(766 / 3,953)$ & 0.106 & $<0.001$ \\
\hline Female & $13.6 \%$ & $(975 / 7,176)$ & $21.8 \%$ & $(644 / 2,949)$ & 0.102 & $<0.001$ \\
\hline Refraining from alcohol & $4.2 \%$ & $(632 / 15,170)$ & $11.0 \%$ & $(760 / 6,902)$ & 0.131 & $<0.001$ \\
\hline Male & $5.6 \%$ & $(448 / 7,994)$ & $14.2 \%$ & $(562 / 3,953)$ & 0.146 & $<0.001$ \\
\hline Female & $2.6 \%$ & $(184 / 7,176)$ & $6.7 \%$ & $(198 / 2,949)$ & 0.099 & $<0.001$ \\
\hline $\begin{array}{l}\text { Refraining from sweets and } \\
\text { soft drinks }\end{array}$ & $13.3 \%$ & $(2,0 I I / I 5, \mid 70)$ & $13.7 \%$ & $(947 / 6,902)$ & 0.006 & 0.348 \\
\hline Male & $12.4 \%$ & $(989 / 7,994)$ & $12.9 \%$ & $(5 \mid 0 / 3,953)$ & 0.008 & $0.4 \mathrm{II}$ \\
\hline Female & $14.2 \%$ & $(1,022 / 7,176)$ & $14.8 \%$ & $(437 / 2,949)$ & 0.007 & 0.453 \\
\hline Refraining from smoking & $11.1 \%$ & $(I, 685 / 15,170)$ & $13.7 \%$ & $(947 / 6,902)$ & 0.037 & $<0.001$ \\
\hline Male & $15.1 \%$ & $(1,207 / 7,994)$ & $18.0 \%$ & $(7 / 0 / 3,953)$ & 0.037 & $<0.001$ \\
\hline Female & $6.7 \%$ & $(478 / 7,176)$ & $8.0 \%$ & $(237 / 2,949)$ & 0.024 & 0.014 \\
\hline Moderate physical exercise & $13.7 \%$ & $(2,07 \mathrm{I} / 15,169)$ & $21.0 \%$ & $(I, 446 / 6,902)$ & 0.092 & $<0.001$ \\
\hline Male & $13.4 \%$ & $(1,075 / 7,993)$ & $20.4 \%$ & $(807 / 3,953)$ & 0.090 & $<0.001$ \\
\hline Female & $13.9 \%$ & $(996 / 7,176)$ & $21.7 \%$ & $(639 / 2,949)$ & 0.096 & $<0.001$ \\
\hline Others & $23.2 \%$ & $(3,5 / 3 / 15,170)$ & $16.0 \%$ & $(1,107 / 6,902)$ & $0.08 I$ & $<0.001$ \\
\hline Male & $23.7 \%$ & $(1,893 / 7,994)$ & $16.8 \%$ & $(663 / 3,953)$ & 0.079 & $<0.001$ \\
\hline Female & $22.6 \%$ & $(1,620 / 7,176)$ & $15.1 \%$ & $(444 / 2,949)$ & 0.085 & $<0.001$ \\
\hline
\end{tabular}

Notes: Phi represents the effect size for chi-square test; "Other" participants answered that they are mindful of other healthy habits; "None" participants answered that they are not mindful of any healthy habits. 
gain and diseases such as diabetes, $51.2 \%$ of inpatients $(7,514 / 14,690)$ and $60.8 \%$ of outpatients $(4,086 / 6,721)$ hoped to receive blood tests regularly $(\mathrm{Q} 21$; phi $=0.090, P<0.001)$, and $64.5 \%$ of inpatients $(9,514 / 14,744)$ and $63.3 \%$ of outpatients $(4,260 / 6,729)$ hoped to weigh themselves regularly (Q22; phi $=0.012, P=0.084)$.

\section{Discussion}

The present study employed a national survey in Japan that evaluated attitudes toward metabolic adverse events among patients with schizophrenia. More than half of outpatients felt obese, and more than half of all respondents hoped to receive regular blood tests to prevent metabolic adverse events. However, a minority of patients were mindful of eating balanced meals and having physical exercise and stated that their doctors encouraged them to have such habits. Our results confirm that patients with schizophrenia are concerned about metabolic adverse events but do not have healthy lifestyle habits.

The differences in dietary patterns between patients with schizophrenia and healthy controls have been reported previously. ${ }^{23,24}$ Inadequate dietary patterns can cause obesity, ${ }^{25} \mathrm{MetS},{ }^{26}$ and cardiovascular events. ${ }^{27}$ In our survey, most outpatients stated that they ate breakfast, lunch, and dinner regularly. However, more than one-third of our respondents ate cake and other sweets at least once a day, and most participants stated that they were not mindful of having a healthy diet. Dietary improvements in patients with schizophrenia might help prevent metabolic adverse events. ${ }^{28}$

Reduced physical activity might play a role in the development of MetS, ${ }^{29}$ and a previous study reported that patients with schizophrenia engaged in physical activity less frequently than healthy controls. ${ }^{30}$ In this survey, approximately half of our respondents ( $55 \%$ of inpatients and $45 \%$ of outpatients) answered that they did not exercise at all. Our results are in accordance with previous research, ${ }^{31}$ which found that $40 \%$ of individuals with schizophrenia report a lack of moderate physical activity, and 75\% report a lack of vigorous physical activity. Although a minority of respondents (inpatients $29.4 \%$, outpatients $39.5 \%$ ) were mindful of having physical exercise, several studies have indicated that regular exercise programs are possible among individuals with schizophrenia and that they can have beneficial effects on their well-being as well as their physical and mental health. ${ }^{32}$

According to our survey, more than half of outpatients reported that they felt obese. Obesity is a growing public health concern, and it is becoming more prevalent among patients with schizophrenia compared with the general population. ${ }^{33-35}$ Previous studies have shown that being overweight is a major risk factor for MetS, cardiovascular diseases, and premature death. ${ }^{36-38}$ Additionally, obesity among patients with schizophrenia is associated with high medication costs, ${ }^{39}$ low self-esteem, poor psychosocial adaptation, ${ }^{40}$ reduced quality of life, ${ }^{41,42}$ negative attitudes toward medication, ${ }^{19}$ and noncompliance with antipsychotic medication regimes. ${ }^{43}$ Although behavioral interventions can effectively prevent and reduce antipsychotic-associated weight gain and cardiometabolic perturbations, ${ }^{15}$ most respondents in this study reported that they were not encouraged by their doctors to perform moderate physical exercise.

More than half of our respondents hoped to receive blood tests regularly to prevent weight gain and diseases such as diabetes. Although patients with severe mental illnesses are less aware of comorbid medical conditions such as heart disease, diabetes, and hypertension, ${ }^{17}$ patients judged disorders such as epilepsy and diabetes as worse than schizophrenia ${ }^{16}$ and described dissatisfaction or deficiency with regard to the care that they received from their health care providers. ${ }^{18}$ Buckley et al showed that most psychiatrists did not routinely monitor their patients' lipid profiles, blood glucose levels, or blood pressure. ${ }^{12}$ We previously reported that most psychiatrists in Japan monitor the lipid profiles and blood glucose levels of their inpatients and outpatients more than twice a year. ${ }^{14}$ Most psychiatrists stated that the frequency at which they monitored patients under antipsychotic treatment was based on their own clinical experience. However, only $20.6 \%$ of respondents stated that this monitoring frequency was sufficient to reduce metabolic risk. It is necessary to disseminate monitoring guidelines with regard to metabolic adverse events because they might make psychiatrists more aware of an integral approach to patients with schizophrenia, thereby increasing the physical health monitoring of these patients. ${ }^{44}$

In Japan, the Mental Health Act seeks to promote the concept of "normalization", establishing mental illness as a disability and encouraging the re-assimilation of psychiatric inpatients back into the community. Although inpatients were encouraged to shift to community-based care, most inpatients did not have enough knowledge of metabolic adverse events. Educational programs seeking to prepare long-term hospitalized patients with schizophrenia for discharge from hospitals are warranted.

The current study also has some limitations. Firstly, our study is limited by the fact that it is cross-sectional rather than prospective in design and lacks data on the actual practices of psychiatrists. This study could not clarify a 
causal relationship between the psychiatrists' practice and attitudes among patients with schizophrenia. Secondly, several potential confounding factors, such as antipsychotic medications, duration of illness, and treatment, were not assessed by our study. Thirdly, mean age of inpatients was older than that of outpatients. Age could affect the results of dietary habits, lifestyle, self-monitoring, knowledge, and medical practices.

\section{Conclusion}

This study showed that only a minority of patients were mindful of eating balanced meals and having physical exercise; however, more than half of patients hoped to prevent weight gain and diabetes. These findings imply that educational efforts $^{45}$ and the promotion of the best pharmacotherapy and monitoring practices ${ }^{46}$ are needed for patients with schizophrenia. Improving attitudes toward metabolic adverse events among these patients might contribute to physical health improvements.

\section{Acknowledgments}

The authors would like to thank all of the coworkers for their skilful contributions to the data collection and management. This work was partially supported by Eisai Co. Ltd., Yoshitomi Pharmaceutical Industries, Dainippon Sumitomo Pharma Co. Ltd., Astellas Pharma Inc., Meiji Seika Pharma Co. Ltd., Eli Lilly Japan, K.K., Otsuka Pharmaceutical Co. Ltd., GlaxoSmithKline K.K., Janssen Pharmaceutical K.K., MSD K.K., Shionogi \& Co. Ltd., Asahi Kasei Pharma Corp., Novartis Pharma Co. Ltd., Takeda Pharmaceutical Co. Ltd., Ono Pharmaceutical Co. Ltd., and Tsumura \& Co. The funders had no role in study design, data collection and analysis, decision to publish, or preparation of the manuscript.

\section{Disclosure}

The authors declare that they have no competing interests in this work.

\section{References}

1. Sugawara N, Yasui-Furukori N, Sato Y, et al. Prevalence of metabolic syndrome among patients with schizophrenia in Japan. Schizophr Res. 2010;123(2-3):244-250.

2. Isomaa B, Almgren P, Tuomi T, et al. Cardiovascular morbidity and mortality associated with the metabolic syndrome. Diabetes Care. 2001; 24(4):683-689.

3. Lakka HM, Laaksonen DE, Lakka TA, et al. The metabolic syndrome and total and cardiovascular disease mortality in middle-aged men. JAMA. 2002;288(21):2709-2716.
4. Wu SH, Liu Z, Ho SC. Metabolic syndrome and all-cause mortality: a meta-analysis of prospective cohort studies. Eur J Epidemiol. 2010; 25(6):375-384.

5. Laursen TM. Life expectancy among persons with schizophrenia or bipolar affective disorder. Schizophr Res. 2011;131(1-3):101-104.

6. McCreadie R, Macdonald E, Blacklock C, et al. Dietary intake of schizophrenic patients in Nithsdale, Scotland: case-control study. BMJ. 1998;317:784-785.

7. Vancampfort D, Probst M, Scheewe T, et al. Relationships between physical fitness, physical activity, smoking and metabolic and mental health parameters in people with schizophrenia. Psychiatry Res. 2013; 207(1-2):25-32.

8. Sugai T, Suzuki Y, Fukui N, et al. Dysregulation of adipocytokines related to second-generation antipsychotics in normal fasting glucose patients with schizophrenia. J Clin Psychopharmacol. 2012;32(3): 390-393.

9. Yasui-Furukori N, Sato Y, Furukori H, Saito M, Nakagami T, Kaneko S. Glucose metabolism in Japanese schizophrenia patients treated with risperidone or olanzapine. J Clin Psychiatry. 2009;70(1):95-100.

10. Sicras-Mainar A, Maurino J, Ruiz-Beato E, Navarro-Artieda R. Prevalence of metabolic syndrome according to the presence of negative symptoms in patients with schizophrenia. Neuropsychiatr Dis Treat. 2014;11:51-57.

11. Newcomer JW, Nasrallah HA, Loebel AD. The Atypical Antipsychotic Therapy and Metabolic Issues National Survey: practice patterns and knowledge of psychiatrists. J Clin Psychopharmacol. 2004;24 (5 Suppl 1):S1-S6.

12. Buckley PF, Miller DD, Singer B, Arena J, Stirewalt EM. Clinicians' recognition of the metabolic adverse effects of antipsychotic medications. Schizophr Res. 2005;79(2-3):281-288.

13. Ketter TA, Haupt DW. Perceptions of weight gain and bipolar pharmacotherapy: results of a 2005 survey of physicians in clinical practice. Curr Med Res Opin. 2006;22(12):2345-2353.

14. Sugawara N, Yasui-Furukori N, Yamazaki M, et al. Psychiatrists' attitudes toward metabolic adverse events in patients with schizophrenia. PLoS One. 2014;9(1):e86826.

15. Caemmerer J, Correll CU, Maayan L. Acute and maintenance effects of non-pharmacologic interventions for antipsychotic associated weight gain and metabolic abnormalities: a meta-analytic comparison of randomized controlled trials. Schizophr Res. 2012;140(1-3):159-168.

16. Rettenbacher MA, Burns T, Kemmler G, Fleischhacker WW. Schizophrenia: attitudes of patients and professional carers towards the illness and antipsychotic medication. Pharmacopsychiatry. 2004;37(3): 103-109.

17. Kilbourne AM, McCarthy JF, Welsh D, Blow F. Recognition of cooccurring medical conditions among patients with serious mental illness. J Nerv Ment Dis. 2006;194(8):598-602.

18. McIntyre RS. Understanding needs, interactions, treatment, and expectations among individuals affected by bipolar disorder or schizophrenia: the UNITE global survey. J Clin Psychiatry. 2009;70 Suppl 3:5-11.

19. Fischel T, Krivoy A, Kotlarov M, et al. The interaction of subjective experience and attitudes towards specific antipsychotic-related adverse effects in schizophrenia patients. Eur Psychiatry. 2013;28(6): 340-343.

20. Karthik MS, Kulhara P, Chakrabarti S. Attitude towards secondgeneration antipsychotics among patients with schizophrenia and their relatives. Hum Psychopharmacol. 2013;28(5):457-465.

21. Statistics and Information Department, Minister's Secretariat, Ministry of Health, Labour and Welfare. Patient Survey. Tokyo, Japan: Ministry of Health, Labour and Welfare; 2008.

22. Sugawara N, Yasui-Furukori N, Sato Y, et al. Comparison of prevalence of metabolic syndrome in hospital and community-based Japanese patients with schizophrenia. Ann Gen Psychiatry. 2011;10:21.

23. Dipasquale S, Pariante CM, Dazzan P, Aguglia E, McGuire P, Mondelli V. The dietary pattern of patients with schizophrenia: a systematic review. J Psychiatr Res. 2013;47(2):197-207. 
24. Tsuruga K, Sugawara N, Sato Y, et al. Dietary patterns and schizophrenia: a comparison with healthy controls. Neuropsychiatr Dis Treat. 2015; 11:1-6.

25. Sugawara N, Yasui-Furukori N, Sato Y, et al. Dietary patterns are associated with obesity in Japanese patients with schizophrenia. BMC Psychiatry. 2014;14:184.

26. Arisawa K, Uemura H, Yamaguchi M, et al. Associations of dietary patterns with metabolic syndrome and insulin resistance: a cross-sectional study in a Japanese population. J Med Invest. 2014;61(3-4):333-344.

27. Oliveira A, Rodríguez-Artalejo F, Gaio R, Santos AC, Ramos E, Lopes C. Major habitual dietary patterns are associated with acute myocardial infarction and cardiovascular risk markers in a southern European population. J Am Diet Assoc. 2011;111(2):241-250.

28. Direk N, Ucok A. Effectiveness of a structured diet program in antipsychotic-induced weight gain in patients with schizophrenia. Int J Psychiatry Clin Pract. 2008;12(3):238-240.

29. Vancampfort D, Sweers K, Probst M, et al. Association of the metabolic syndrome with physical activity performance in patients with schizophrenia. Diabetes Metab. 2011;37(4):318-323.

30. Ratliff JC, Palmese LB, Reutenauer EL, Liskov E, Grilo CM, Tek C. The effect of dietary and physical activity pattern on metabolic profile in individuals with schizophrenia: a cross-sectional study. Compr Psychiatry. 2012;53(7):1028-1033.

31. Faulkner G, Cohn T, Remington G. Validation of a physical activity assessment tool for individuals with schizophrenia. Schizophr Res. 2006; 82(2-3):225-231.

32. Gorczynski P, Faulkner G. Exercise therapy for schizophrenia. Cochrane Database Syst Rev. 2011;5:CD004412.

33. Allison DB, Casey DE. Antipsychotic-induced weight gain: a review of the literature. J Clin Psychiatry. 2001;62(7):22-31.

34. Susce MT, Villanueva N, Diaz FJ, de Leon J. Obesity and associated complications in patients with severe mental illnesses: a cross-sectional survey. J Clin Psychiatry. 2005;66(2):167-173.

35. Dickerson FB, Brown CH, Kreyenbuhl JA, et al. Obesity among individuals with serious mental illness. Acta Psychiatr Scand. 2006;113(4): 306-313.
36. Martin RL, Cloninger CR, Guze SB, Clayton PJ. Mortality in a follow-up of psychiatric outpatients, I. Total mortality. Arch Gen Psychiatry. 1985;42(1):47-54.

37. Allebeck P. Schizophrenia: a life-shortening disease. Schizophr Bull. 1989;15(1):81-89.

38. Leucht S, Burkard T, Henderson J, Maj M, Sartorius N. Physical illness and schizophrenia: a review of the literature. Acta Psychiatr Scand. 2007;116(5):317-333.

39. Chwastiak LA, Rosenheck RA, McEvoy JP, et al. The impact of obesity on health care costs among persons with schizophrenia. Gen Hosp Psychiatry. 2009;31(1):1-7.

40. De Hert M, Peuskens B, van Winkel R, et al. Body weight and self-esteem in patients with schizophrenia evaluated with B-WISE. Schizophr Res. 2006;88(1-3):222-226.

41. Allison DB, Mackell JA, McDonnell DD. The impact of weight gain on quality of life among persons with schizophrenia. Psychiatr Serv. 2003;54(4):565-567.

42. Sugawara N, Yasui-Furukori N, Sato Y, et al. Body mass index and quality of life among outpatients with schizophrenia in Japan. BMC Psychiatry. 2013;13:108.

43. Weiden PJ, Mackell JA, McDonnell DD. Obesity as a risk factor for antipsychotic noncompliance. Schizophr Res. 2004;66(1):51-57.

44. Bobes J, Alegría AA, Saiz-Gonzalez MD, Barber I, Pérez JL, Saiz-Ruiz J. Change in psychiatrists' attitudes towards the physical health care of patients with schizophrenia coinciding with the dissemination of the consensus on physical health in patients with schizophrenia. Eur Psychiatry. 2011;26(5):305-312.

45. Lindenmayer JP, Khan A, Wance D, Maccabee N, Kaushik S, Kaushik S. Outcome evaluation of a structured educational wellness program in patients with severe mental illness. J Clin Psychiatry. 2009;70(10): 1385-1396.

46. Marder SR, Essock SM, Miller AL, et al. Physical health monitoring of patients with schizophrenia. Am J Psychiatry. 2004;161(8): 1334-1349. 


\section{Supplementary material}

Q1. How often did you drink soft drinks (e.g., cola) over the past year?
$\square$ Not at all
$\square$ More than once a month
$\square$ More than once a week
$\square$ Every day

Q2. For inpatients

How much do you eat (three meals a day $=100 \%)$ ?

$$
\begin{aligned}
& \square 100 \% \\
& \square 90 \% \\
& \square 80 \% \\
& \square 70 \% \\
& \square 60 \% \\
& \square 50 \% \text { or less }
\end{aligned}
$$

For outpatients

Do you regularly eat breakfast, lunch, and dinner?

Yes/No

Q3. Do you eat cake or other sweets more than once a day?

Yes/No

Q4. For inpatients

Have you been warned that you eat too many snacks by the people Yes/No around you?

For outpatients

Have you been warned that you eat too much by your family or friends? Yes/No

Q5. For inpatients

When you go out or stay out overnight, do you generally take sweets? Yes/No

For outpatients

When you go out, do you generally take sweets?

Yes/No

Q6. Are you always hungry?

Yes/No

Q7. Do you feel that you gained weight over the past year?

Yes/No

Q8. How often did you go out?

$\square$ Every day

$\square$ More than once a week

$\square$ More than once a month

$\square$ Once a month or less

Q9. For outpatients only

Do you cook or do housework by yourself?

Yes/No

Q10. How often do you exercise?

$\square$ Every day

$\square$ More than once a week

$\square$ Once a week

$\square$ Not at all

Q11. How often do you watch television?

$\square$ Every day

$\square$ Sometimes

$\square$ Not at all

Q12. Has your doctor told you how your current medication can cause side $\quad$ Yes/No effects such as weight gain?

Q13. For inpatients

How often is your body weight measured at the hospital?

$\square$ Every day

$\square$ Once a week 
For outpatients

How often is your body weight measured at the hospital?

Q14. For inpatients

How often do you have blood tests at the hospital?

For outpatients

How often do you have a blood test at the hospital?

Q15. For outpatients only

How often do you weigh yourself?

Q16. Do you know the term "metabolic syndrome"?

Q17. Do you know the terms "BMI" or "body mass index"?

Q18. Which has your doctor encouraged you to be mindful of (multiple answers allowed)

Q19. Of which are you mindful? (multiple answers allowed) $\square$ Once a month

$\square$ At least once every six months

$\square$ At least once a year

$\square$ Not at all

$\square$ Every visit

$\square$ At least once every three months

$\square$ At least once every six months

$\square$ At least once a year

$\square$ Not at all

$\square$ Every month

$\square$ At least once every three months

$\square$ At least once every six months

$\square$ At least once a year

$\square$ Not at all

$\square$ Every visit

$\square$ At least once every three months

$\square$ At least once every six months

$\square$ At least once a year

$\square$ Not at all

$\square$ Every day

$\square$ More than once a week

$\square$ More than once a month

$\square$ Not at all

Yes/No

Yes/No

$\square$ Eating balanced meals and appropriate amounts of food

$\square$ Refraining from alcohol

$\square$ Refraining from sweets or soft drinks

$\square$ Refraining from smoking

$\square$ Moderate physical exercise

$\square$ Others

$\square$ Eating balanced meals

$\square$ Refraining from fast food

$\square$ Refraining from soft drinks (e.g., cola)

$\square$ Refraining from alcohol

$\square$ Refraining from smoking

$\square$ Sleeping enough

$\square$ Moderate physical exercise

Figure SI (Continued) 
$\square$ Others

$\square$ None

Q20. Do you feel that you are obese?

Yes/No

Q21. Do you hope to receive blood tests regularly to prevent weight gain

Yes/No and diseases such as diabetes?

Q22. Do you hope to weigh yourself regularly to prevent weight gain

Yes/No and diseases such as diabetes?

Figure SI Questionnaire about attitudes toward metabolic adverse events in patients with schizophrenia.

\section{Publish your work in this journal}

Neuropsychiatric Disease and Treatment is an international, peerreviewed journal of clinical therapeutics and pharmacology focusing on concise rapid reporting of clinical or pre-clinical studies on a range of neuropsychiatric and neurological disorders. This journal is indexed on PubMed Central, the 'PsycINFO' database and CAS, and is the official journal of The International Neuropsychiatric Association (INA). The manuscript management system is completely online and includes a very quick and fair peer-review system, which is all easy to use. Visit http://www.dovepress.com/testimonials.php to read real quotes from published authors.

\footnotetext{
Submit your manuscript here: http://www.dovepress.com/neuropsychiatric-disease-and-treatment-journal
} 